\title{
BENEFIT EVALUATION OF ENERGY-SAVING AND EMISSION REDUCTION IN CONSTRUCTION INDUSTRY BASED ON ROUGH SET THEORY
}

\begin{abstract}
Achieving energy conservation and emission reduction in the industry is an inevitable way to promote harmony between society and nature and achieve sustainable human development. China's infrastructure construction industry is developing rapidly. Still, there is a lack of a well-established industry standard for evaluating the potential and level of energy reduction in infrastructure construction. A severe lack of quantitative research on energy-saving and $\mathrm{CO}_{2}$ outflow decreases the benefits of green development advances. This study takes the energy conservation and outflow decrease of construction waste slurry treatment in Guangdong Province, China, as the background, establishes an evaluation system with three rule levels: social, economic, and environmental, and adopts rough set theory to determine the weights of each index to ensure the objectivity of each index. According to the recommendations of the carbon emission calculation guidelines, select the relevant data to evaluate the energy-saving and emission reduction benefits of the new green construction technology of grouted piles in a road project in Guangdong Province. The results show that the development level and potential of energy saving and emission reduction technology in the construction sector in Guangdong Province are increasing year by year. It's potential changes with the increase or decrease of highway mileage, and it is an urgent need to increase investment in pollution control. The research results can evaluate the benefits of energy-saving and carbon dioxide emission reduction in the construction industry, also be used as a reference to assess energy-saving and emission reduction in the construction industry in other countries.
\end{abstract}

Keywords: rough set theory, construction slurry, energy-saving and emission reduction, benefit analysis

\section{Introduction}

The development of energy-saving and emission reduction in the industry is of great significance to guarantee its improvement. In today's globalization, the Chinese construction industry's sustainable development will significantly impact energy consumption and carbon emissions worldwide. Zhang et al. [1] studied this based on the Global Vector Auto-Regression model. It appears that the growth of China's construction industry may lead to different responses to energy consumption carbon emanations from entirely other nations. With the fast advancement of China's economy and the progressive increment of the construction industry's overall scale, it must be paid attention to its impact on the environment. The demand for green construction technology is also gradually increasing. To achieve the goal of the Sino-US Joint Bulletin on Climate change [2], China should reach its crest $\mathrm{CO}_{2}$ outflows by 2030 , which is crucial to achieving the Paris

\footnotetext{
${ }^{1}$ Shenzhen Engineering Company of CREGC, Shenzhen 518000 China, email: zzjlwtg@ outlook.com (Z.Z.)

${ }^{2}$ School of Civil Engineering, Architecture and Environment, Xihua University, Chengdu 610039 China, email: zx20132001028@outlook.com (X.Z.); 18380459516@163.com (X.Y.)

*Corresponding author: zx20132001028@ outlook.com
} 
Agreement's objective of constraining worldwide warming to underneath two degrees Celsius [3]. According to the report of The Intergovernmental Panel on Climate Change (IPCC) $[4,5]$, the research on energy consumption and carbon emissions in the energy industry and chemical industry has been relatively prosperous. But the scientific research on energy conservation and $\mathrm{CO}_{2}$ outflow decrease in the construction industry is not sufficient. There is a gap in the study on the potential and benefits of energy conservation and carbon dioxide emission reduction in construction links and construction technologies. Therefore, it is vital to set up a scientific evaluation framework for the specific construction relations and a quantitative ponder on the benefits of energy-saving and emission reduction of green construction technology.

Many studies area on $\mathrm{CO}_{2}$ emissions in China that divide the scope of research by geographic [6-8]. The scientific estimation of industry $\mathrm{CO}_{2}$ emissions are mainly focused on the iron and steel industry [9], transport industry [10], mining industry [11], power industry [12], manufacturing industry [13], and so on. In the construction industry, Shi et al. [14] studied the drivers of carbon outflows in the Chinese construction industry. Yang et al. [15] assessed Chinese construction carbon emissions and made some carbon reduction policy recommendations based on their findings. Studies in a traditional industry and agriculture [16-18], energy and materials industries [19-21], etc., have shown that the development and application of new technologies can play a huge role in promoting the greening of industries. However, to actively advance the advancement of energy-saving and $\mathrm{CO}_{2}$ outflow decrease within the construction industry, it is also necessary to identify the energy-saving and emission reduction potential of more detailed construction modules and quantify the energy-saving and outflow diminishment benefits of the significant green development innovation. Make it form a joint force at the social and economic level. Therefore, this paper evaluates the energy-saving and emission reduction potential of construction slurry in Guangdong Province.

This study constructs an evaluation model from three viewpoints of the society, economy, and ecological environment. It calculates the importance of each index data in the system based on rough set theory. Finally, each index weight is normalized to evaluate the energy-saving and emission reduction potential of building mud treatment in Guangdong Province. Simultaneously, the energy-saving and carbon emission reductions benefits of green treatment of building mud are quantified.

\section{Methods}

\section{Construct the evaluation system of building mud energy saving and $\mathrm{CO}_{2}$ outflow decrease}

The energy-saving and $\mathrm{CO}_{2}$ outflow decrease of waste mud treatment in engineering construction are deeply related to the economic, social, and ecological environment. To construct the evaluation system of building mud energy saving and $\mathrm{CO}_{2}$ outflow decrease, it is essential to comprehensively consider the three aspects of the economy, society, and ecological environment. Based on the rough set theory and referring to other industries' relevant research, the building mud energy saving and emission reduction evaluation system constructed in this paper includes social subsystem, economic subsystem, and environmental subsystem [22]. These three subsystems restrict each other and jointly determine the development of energy-saving and emanation lessening of squander mud treatment within the construction industry. 
In the economic subsystem, the ultimate goal is to consider all aspects of constraints to improve economic benefits comprehensively. It can not only realize the effective treatment of construction waste mud to alleviate the pressure of waste mud treatment brought by the massive growth of infrastructure projects but also meet the construction industry's requirements. In the ecological environment subsystem, the purpose is to maintain the balance of the environmental environment. By encouraging the development and use of new technologies to improve emission reduction, increase the level of waste mud and sewage treatment, improve the efficiency of pollution control, and finally reduce the pressure of environmental protection. At the same time, it is also necessary to consider the changes in the cost of energy-saving and emission reduction treatment caused by natural disasters, such as typhoons. In the social subsystem, the goal is to realize the standardization and high efficiency of building waste mud treatment to meet the development of infrastructure and reduce the environmental pollution and safety risks caused by waste mud. Only when the three subsystems meet their respective goals and maximize the evaluation system's broad interests can the development of energy-saving and emission reduction in the construction industry be benign [23].

Review the relevant literature, combined with the development status of infrastructure construction and emission reduction technology in Guangdong Province, China, and we choose to get each subsystem's indicators. The results show in Table 1.

Table 1

Three subsystems, indexes, and unit

\begin{tabular}{|c|c|c|}
\hline Rule layer & Index & Unit \\
\hline \multirow{4}{*}{$\begin{array}{c}\text { Economic } \\
\text { subsystem }\end{array}$} & Increase in highway mileage U11 & {$[\mathrm{km} /$ year $]$} \\
\cline { 2 - 3 } & Gross domestic product index U12 & {$[-]$ The qualitative analysis } \\
\cline { 2 - 3 } & GDP highway mileage growth U13 & {$\left[\mathrm{km} / 10^{10}\right.$ yuan $\left.^{*}\right]$} \\
\cline { 2 - 3 } & Added-value of construction U14 & {$\left[10^{8}\right.$ yuan] } \\
\hline \multirow{4}{*}{$\begin{array}{c}\text { Environmental } \\
\text { subsystem }\end{array}$} & The proportion of GDP of the tertiary industry is U15 & {$[\%]$} \\
\cline { 2 - 3 } & Total water consumption U21 & {$\left[10^{6} \cdot \mathrm{m}^{3}\right]$} \\
\cline { 2 - 3 } & Industrial water consumption U22 & {$\left[10^{6} \cdot \mathrm{m}^{3}\right]$} \\
\cline { 2 - 3 } & Total effluent discharge U23 & {$\left[10^{4}\right.$ tonne of $]$} \\
\cline { 2 - 3 } $\begin{array}{c}\text { Social } \\
\text { subsystem }\end{array}$ & Thvestment in wastewater treatment U24 & {$\left[10^{4}\right.$ yuan $]$} \\
\cline { 2 - 3 } & Per capita annual electricity consumption U32 & {$[\%]$} \\
\cline { 2 - 3 } & Per capita daily electricity consumption U33 & {$[\mathrm{kWh} /($ person $\cdot$ year) $]$} \\
\hline
\end{tabular}

${ }^{*} 1$ yuan $\left(\right.$ January 2021) $=0.1288 €,{ }^{* *}$ tonne $=\mathrm{Mg}=10^{6} \mathrm{~g}$

\section{Partition of an ideal exponential set}

The excellent division of the index set is the necessary basis for evaluating objectivity and accuracy. Before assessing the energy-saving and $\mathrm{CO}_{2}$ outflow decrease potential of waste mud treatment in the construction industry, it is divided according to China's actual situation as a whole and each region. According to international standards, the range of indicators is first determined, but those that have not formed a unified standard are divided according to industry habits or actual development [24, 25]. Considering the real situation of Guangdong Province in China, the impact of some indicators such as typhoon on construction needs to be qualitatively analysed. The index set is divided into five grades range from $\mathrm{I}$ to $\mathrm{V}$. The higher the score, the greater the development potential of energy-saving and $\mathrm{CO}_{2}$ outflow decrease in this region, and the more urgent the 
development needs. The evaluation standards of energy conservation and emission reduction of building mud in the Guangdong construction industry are shown in Table 2.

Table 2

Evaluation criteria of indicators

\begin{tabular}{|c|c|c|c|c|c|}
\hline Index & I & II & III & IV & V \\
\hline U11 & $<1500$ & $1500-3000$ & $3000-5000$ & $5000-7000$ & $>7000$ \\
\hline U12 & \multicolumn{5}{|c|}{- The qualitative analysis } \\
\hline U13 & $>35$ & $35-25$ & $25-15$ & $15-5$ & $<5$ \\
\hline U14 & $<600$ & $600-1000$ & $1000-1500$ & $1500-1800$ & $>1800$ \\
\hline U15 & $<40$ & $40-50$ & $50-60$ & $60-75$ & $>75$ \\
\hline U21 & $>450$ & $450-300$ & $300-200$ & $200-100$ & $<100$ \\
\hline U22 & $>130$ & $130-90$ & $90-60$ & $20-60$ & $<20$ \\
\hline U23 & $<10000$ & $10000-100000$ & $100000-300000$ & $300000-700000$ & $>700000$ \\
\hline U24 & $>90000$ & $90000-50000$ & $50000-10000$ & $10000-5000$ & $<5000$ \\
\hline U25 & $>85$ & $85-75$ & $-7 h e$ qualitative analysis & $<5$ \\
\hline U31 & $>5500$ & $5500-4200$ & $4200-3100$ & $3100-2000$ & $<2000$ \\
\hline U32 & $>18$ & $18-14$ & $14-11$ & $11-8$ & $<8$ \\
\hline U33 & \multicolumn{7}{|l|}{}
\end{tabular}

\section{Rough set theory}

Polish mathematician Professor Z. Pawlak put forward a rough set theory as a data analysis tool [26, 27] in 1982 and extended it in the follow-up research [28, 29]. As a new tool to deal with uncertain and fuzzy data, the rough set theory does not need any prior knowledge, avoids the dependence and influence on subjectivity such as expert experience, and can describe the problem of uncertainty relatively objectively [24].

For information systems $I=(U, A), X \subseteq A$ could be a subset of traits and $x \subseteq A$ is a trait. The significance of $x$ to $X$ is the increase in resolution with the addition of $X$ attribute in $x$, which is expressed $\operatorname{as~} \operatorname{Sig}_{x}(X)$. The significance of $x$ itself is described in $\operatorname{Sig}(x)$. The calculation process for both is as follows [24]:

$$
\begin{aligned}
& \operatorname{Sig}_{x}(X)=1-\frac{|X \cup\{x\}|}{|X|} \\
& \operatorname{Sig}(x)=1-\frac{|\{x\}|}{(\operatorname{Card}(U))^{2}}
\end{aligned}
$$

where $U / X=\left\{X_{1}, X_{2}, \ldots, X_{n}\right\}$, and $|X|=\sum_{i=1}^{n}\left|X_{i}\right|^{2}=\sum_{i=1}^{n}\left(\operatorname{Card}\left(X_{i}\right)\right)^{2}, \operatorname{Card}(X)$ denotes the cardinality of the set $X$.

Considering the importance of $x$ to $X$ and the importance of $x$ itself, the final attribute importance of $S I G(x), \operatorname{SIG}(x)$ reaction attribute $x$ is obtained by adding $\operatorname{Sig}_{x}(X)$ and $\operatorname{Sig}(x)$ :

$$
\operatorname{SIG}(x)=\operatorname{Sig}_{x}(X)+\operatorname{Sig}(x)
$$

After the final importance of each attribute is obtained, the weight of each feature can be obtained by normalizing it: 


$$
w(x)=\frac{S I G(x)}{\sum S I G(x)}
$$

\section{Initial data, weight of data, and calculation result}

According to Table 1, the relevant data of Guangdong Province from 2006 to 2017 are chosen to calculate each index's weight. The evaluation index data were obtained from the National Bureau of Statistics and the Department of Civil Affairs Department and are summarized in Table 3 after relevant calculations.

Actual data corresponding to each indicator from 2006 to 2017

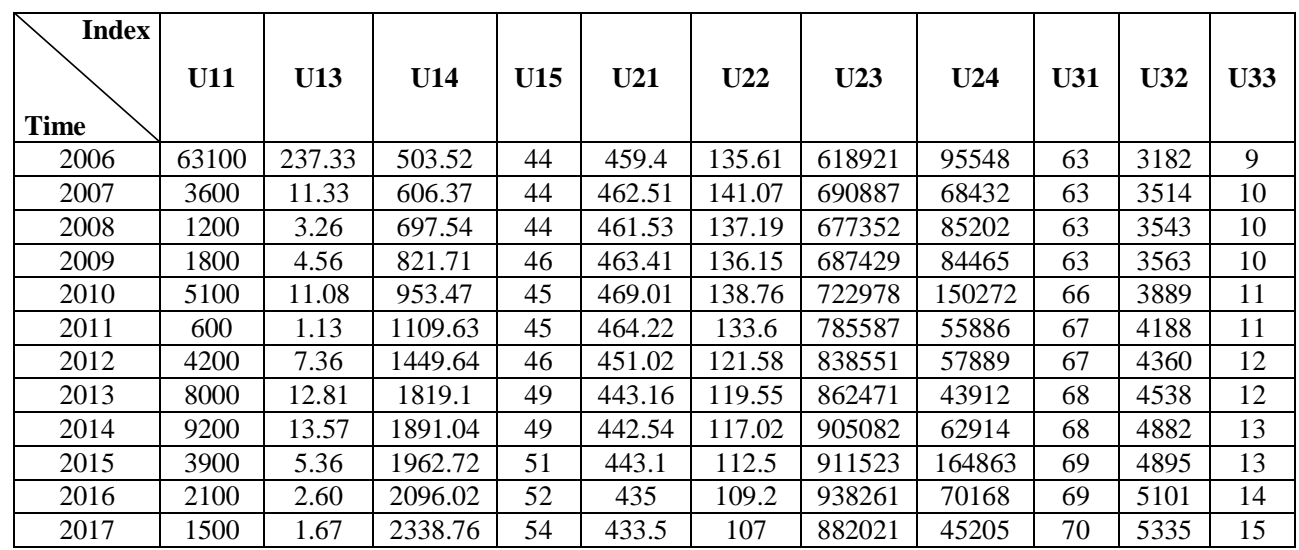

The weights of each index from 2006 to 2017

Table 4

\begin{tabular}{|c|c|c|c|c|c|}
\hline Rule layer & Index & Sig $_{\boldsymbol{x}}(\boldsymbol{X})$ & $\boldsymbol{S i g}(\boldsymbol{x})$ & $\boldsymbol{S I G}(\boldsymbol{x})$ & The weight \\
\hline \multirow{4}{*}{$\begin{array}{c}\text { Economic } \\
\text { subsystem }\end{array}$} & $\mathrm{U} 11$ & 0.143 & 0.736 & 0.878 & 0.092 \\
\cline { 2 - 6 } & $\mathrm{U} 12$ & 0.63 & 0 & 0.63 & 0.066 \\
\cline { 2 - 6 } & $\mathrm{U} 13$ & 0 & 0.488 & 0.488 & 0.051 \\
\cline { 2 - 6 } & $\mathrm{U} 14$ & 0 & 0.620 & 0.620 & 0.065 \\
\hline \multirow{4}{*}{$\begin{array}{c}\text { Environmental } \\
\text { subsystem }\end{array}$} & $\mathrm{U} 15$ & 0 & 0.256 & 0.256 & 0.026 \\
\cline { 2 - 6 } & $\mathrm{U} 21$ & 0 & 0.388 & 0.388 & 0.089 \\
\cline { 2 - 6 } & $\mathrm{U} 22$ & 0 & 0.405 & 0.405 & 0.092 \\
\cline { 2 - 6 } & $\mathrm{U} 23$ & 0 & 0.339 & 0.339 & 0.077 \\
\hline \multirow{3}{*}{$\begin{array}{c}\text { Social } \\
\text { subsystem }\end{array}$} & $\mathrm{U} 25$ & 0.25 & 0.488 & 0.738 & 0.017 \\
\cline { 2 - 6 } & $\mathrm{U} 31$ & 0 & 0.339 & 0.146 & 0.073 \\
\cline { 2 - 6 } & $\mathrm{U} 32$ & 0 & 0.405 & 0.339 & 0.053 \\
\hline
\end{tabular}

According to the five standard states in Table 2, Table 3 is divided into five levels representing the development potential and development level of building mud energy saving and $\mathrm{CO}_{2}$ outflow decrease in Guangdong from bad to ideal. The gradient ranges of these five levels are different, and each index's variation range is also diverse [24]. Referring to the relevant literature and combining the actual development of energy-saving 
and $\mathrm{CO}_{2}$ outflow decrease of building mud in Guangdong Province, the three regular layers' weights are $0.3,0.5$, and 0.2 , respectively. The final attribute importance of each attribute is calculated in the previous paragraph, and its weight is obtained after normalization. The calculated results are shown in Table 4.

Table 5

The amount of investment in road and bridge construction from 2006 to 2017 and the evaluation results of energy saving and emission reduction in Guangdong province

\begin{tabular}{|c|c|c|c|c|c|}
\hline Items & Time & $\begin{array}{c}\text { Evaluation } \\
\text { level }\end{array}$ & $\begin{array}{c}\text { Investment in road and } \\
\text { bridge construction in } \\
\text { Guangdong Province }\end{array}$ & $\begin{array}{c}\text { Total investment in } \\
\text { road and bridge } \\
\text { construction in China }\end{array}$ & $\begin{array}{c}\text { Increase highway } \\
\text { mileage in Guangdong } \\
\text { Province }\end{array}$ \\
\hline Unit & [year] & {$[-]$} & $\begin{array}{c}{\left[\mathbf{1 0}^{9} \text { yuan] }\right.} \\
\text { use Chinese yuan only }\end{array}$ & $\begin{array}{c}{\left[\mathbf{1 0}^{\mathbf{9}} \text { yuan] }\right.} \\
\text { use Chinese yuan only }\end{array}$ & {$[\mathbf{k m ]}$} \\
\hline \multirow{6}{*}{ Value } & 2006 & 2.024 & 11.182 & 299.99 & 63100 \\
\cline { 2 - 6 } & 2007 & 2.226 & 10.921 & 298.9 & 3600 \\
\cline { 2 - 6 } & 2008 & 2.094 & 10.505 & 358.41 & 1200 \\
\cline { 2 - 6 } & 2009 & 2.185 & 15.503 & 495.06 & 1800 \\
\cline { 2 - 6 } & 2010 & 2.09 & 32.791 & 669.57 & 5100 \\
\cline { 2 - 6 } & 2011 & 2.099 & 20.816 & 707.91 & 600 \\
\cline { 2 - 6 } & 2012 & 2.261 & 23.997 & 740.25 & 4200 \\
\cline { 2 - 6 } & 2013 & 2.831 & 24.534 & 835.56 & 9000 \\
\cline { 2 - 6 } & 2014 & 2.662 & 20.402 & 764.39 & 3900 \\
\cline { 2 - 6 } & 2015 & 2.337 & 30.343 & 741.4 & 2100 \\
\cline { 2 - 6 } & 2016 & 2.381 & 23.282 & 756.43 & 1500 \\
\cline { 2 - 6 } & 2017 & 2.549 & 29.886 & 699.67 & \\
\hline
\end{tabular}

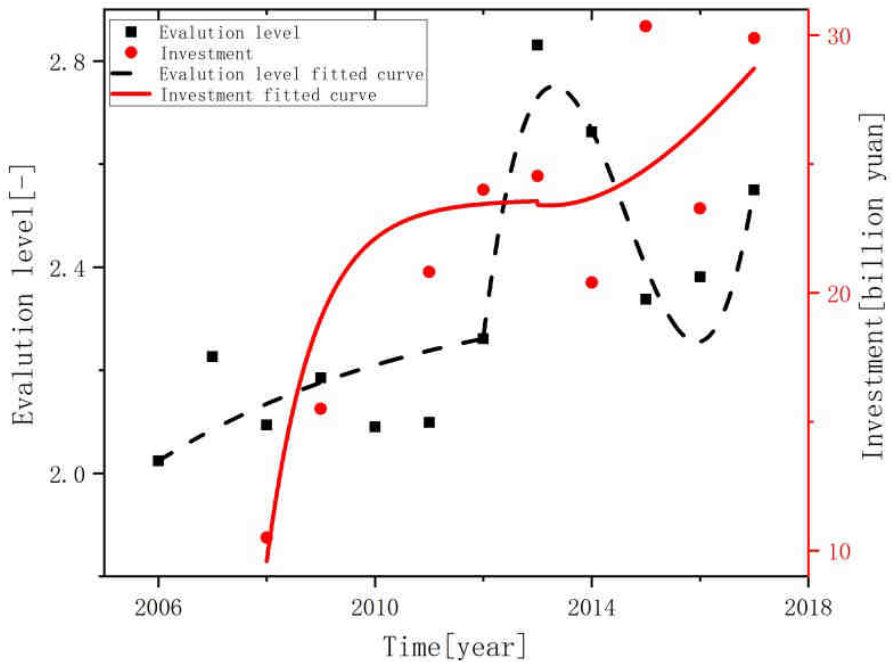

Fig. 1. Evaluation of road and bridge construction investment and mud treatment energy saving and emission reduction in Guangdong province from 2006 to 2017

The weights the indexes have gotten in Table 4 are multiplied by the corresponding index levels for each year and added together to obtain the final evaluation results in Table 5. The Ministry of Housing and Urban-Rural Development of the People's Republic of 
China (MOHURD), the published investment amount, and evaluation results of road and bridge construction in Guangdong Province and the whole of China are listed and compared. The specific change law is shown in Figures 1 and 2.

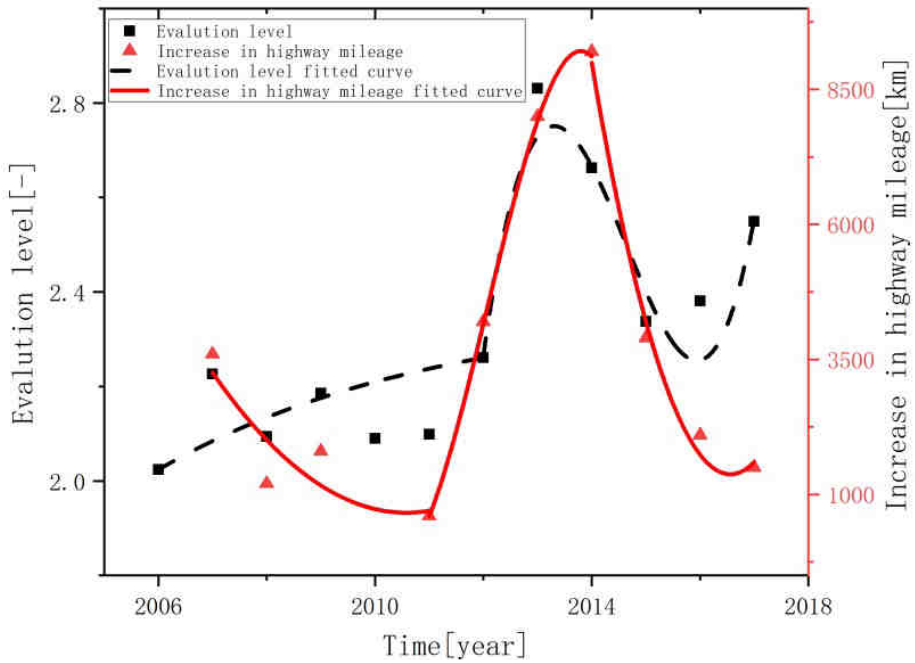

Fig. 2. Evaluation of highway mileage growth and mud treatment energy saving and emission reduction in Guangdong province from 2006 to 2017

As can be seen from the figure, the investment and evaluation results of road and bridge construction in Guangdong Province can be divided into three stages. The amount of investment in transportation construction has increased from rapid growth to slow growth and finally kept fluctuating and rising. The evaluation results of energy-saving and emission reduction of building mud treatment in Guangdong Province rose slowly from the beginning to rapid growth. Finally, they returned to the upward trend after a short period of sharp decline.

Before 2011, the investment in road and bridge construction is increased, while the growth of highway mileage is relatively low, although the corresponding evaluation results have improved, the change is slow. From 2011 to 2013, the investment in road and bridge construction remains within a broad range. Still, the highway mileage increases significantly, and the evaluation results of energy-saving and emission reduction are also improved rapidly. After 2013, the evaluation results of emission reduction quickly decreased, which may be related to the policies on energy conservation and emission reduction in the comprehensive work plan for energy conservation and emission reduction during the Twelfth five-year Plan period. In 2015, which is also the last year of the 12th five-year Plan stage, the mileage of new roads decreased significantly, and the investment in sewage treatment in Table 3 increased exponentially. However, after 2015, with the rapid development of the construction industry and the increase in road and bridge construction investment, the potential and demand for energy saving and emission reduction of mud treatment in the Guangdong construction industry have increased again. 


\section{New energy-saving and emission reduction technologies}

\section{Engineering technical background}

In order to promote energy-saving and emission reduction in the construction industry, some new green construction technologies have been tested in practical projects. Only the construction technology that conforms to the social, economic, and environmental goals and has comprehensive benefits can provide real benefits for the construction industry's energy-saving and emission reduction development. There may be some new green construction technologies that can meet the result of energy-saving and emission reduction in the construction industry, however, due to the lack of quantitative research on the benefits of energy-saving and emission reduction of construction technology. Many new construction technologies lack a theoretical basis when popularizing, which leads to low promotion efficiency and indirectly hinders the industry level's improvement.

The traditional treatment method of construction mud is directly transported and discharged and allowed to run its course. This original and straightforward treatment method is easy to cause significant environmental pollution and produce adverse social influence. A new construction method has been developed to construct the Jiangmen section of Guangfojiang Fast Passage of China Railway No. 2 Engineering Co., LTD. The waste mud generated during the construction of 724 cast-in-place piles of the project has been green treated. Its specific construction process is composed of three modules, as shown in Figure 3.

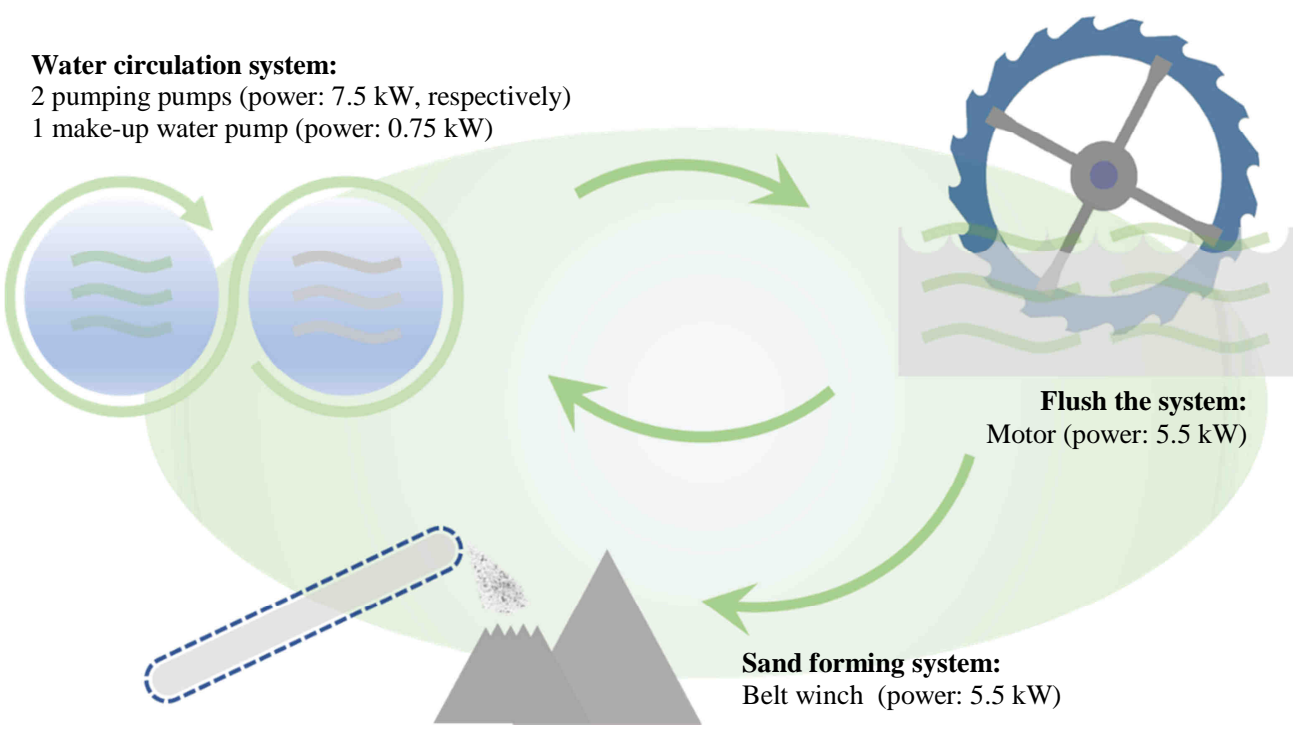

Fig. 3. The green circulating mud treatment system

After the flushing backflow system washes away the building's waste mud with high-pressure water, the separated sand, debris, and muddy liquid are classified through the screen and impeller. Sand and gravel are transported to the air and sunshine field by belt driving winch and put into the project for continuous use after drying and inspection. Mud 
water is recycled after settling through the water storage and circulation area. Discharge a small number of other sundries that cannot be recycled. The water storage circulation system has two water tanks, one for storing clear water and turbid water. After the turbid water is first placed in the turbid water tank, it is stored in the clear water tank, and the clear water enters the flushing reverse drainage system through the pump. The sand and gravel transported by belt drive hoisting are tested and distributed to different construction links according to particle size gradation in the sand separation system.

Compared with the traditional construction mud treatment method, the new construction method has obvious economic benefits and meets the financial system's requirements. Simultaneously, the modular layout enables it to adapt to the complex construction environment to meet the social network requirements. But its specific environmental protection benefit still needs further quantification research.

\section{Calculation method}

According to the recommendations of IPCC Carbon Emission Calculation Guidelines [4], combined with the energy consumption characteristics of construction links, each construction link's energy consumption is calculated according to electricity. The calculation formula of energy consumption carbon emission is as follows:

$$
E=\sum_{i=1}^{n}\left(e_{i} \cdot p_{i}\right)
$$

where $E$ is the comprehensive energy consumption of the mud treatment system (calculated according to electricity), $n$ is the type of energy used in the construction and production process, $e_{i}$ is the specific equipment and tools that consume the type of $i$ energy, and $p_{i}$ is the conversion coefficient of the type of $i$ energy.

When calculating comprehensive energy consumption and carbon emission, it is converted to standard coal equivalent:

$$
\begin{gathered}
T_{c}=E \cdot L \\
T_{\mathrm{co}_{2}}=E \cdot L^{\prime}
\end{gathered}
$$

where: $T_{c}$ is the amount converted to standard coal for energy consumption, $T_{c_{2}}$ is the carbon dioxide emissions. $L$ and $L^{\prime}$ are carbon emission coefficient and $\mathrm{CO}_{2}$ emission coefficient respectively.

According to the 2017 energy consumption data released by the National Bureau of Statistics of China, the amount of standard coal converted from various energy types in that year was $4.485 \cdot 10^{9}$ tonne of coal equivalent (tce). In 2017 , it consumed $6.482 \cdot 10^{12} \mathrm{kWh}$ of electricity, including $4.663 \cdot 10^{9} \mathrm{kWh}$ of firepower, accounting for $71.93 \%$ of the total power consumption. Of the $3.857 \cdot 10^{8}$ tonne of raw coal consumed, $19.025 \cdot 10^{6}$ tonne were used for power generation, accounting for $49.26 \%$ of the total. It consumes $5.875 \cdot 10^{8}$ tonne of oil, $2.81 \cdot 10^{6}$ tonne of which is used for power generation, accounting for 0.48 percent of the total.

According to the above data, it can be calculated that the converted amount of standard coal consumed by thermal power in 2017 is $1.339 \cdot 10^{9}$ tce. And the ratio between it and the consumption of thermal power in that year is the converted standard coal coefficient of electricity, namely the carbon emission coefficient of electricity consumption: 


$$
L=\frac{1.339 \cdot 10^{9}}{4.663 \cdot 10^{3} \cdot 10^{6}}=0.287 \mathrm{kgce} / \mathrm{kWh}
$$

That is, each kilowatt-hour ( $\mathrm{kWh}$ ) saved is equal to 0.287 kilogram of coal equivalent (kgce). The emission coefficient of $\mathrm{CO}_{2}$ produced by the complete combustion of standard coal is 0.67 , recommended by the Energy Research Institute of The National Development and Reform Commission of China. According to the relative molecular weight of carbon 12 , the relative molecular weight of carbon dioxide is 44 . The emission coefficient of $\mathrm{CO}_{2}$ produced by the chemical equation based on carbon combustion is:

$$
L^{\prime}=L \cdot 0.67 \cdot \frac{44}{12}=0.705 \quad \mathrm{kgCO}_{2} / \mathrm{kWh}
$$

For every $1 \mathrm{kWh}$ of electricity saved, it is equivalent to 0.705 kilogram of $\mathrm{CO}_{2}$ emission reduction $\left(\mathrm{kgCO}_{2}\right)$.

Taking the Jiangmen section of Guangfojiang Fast Passage of China Railway No. 2 Engineering Co., LTD. as an example, a new construction treatment technology is used to treat the waste mud in the production process cast-in-place pile, and the benefits of energy-saving and emission reduction are quantitatively studied. The average depth of 724 cast-in-place piles in this project is 40 meters, and the diameter is $1.3 \mathrm{~m}$. The waste mud generated is calculated as two times the pile.

Some similar products on the market can separate the mud from solid and liquid. After the separation, the mud paste has low water content and accounts for about $60 \%$ of the original mud. The machine's power is $9 \mathrm{~kW}$, and the mud treatment capacity is $20 \mathrm{~m}^{3} / \mathrm{h}$. The separated water accounts for $40 \%$ and needs to be discharged into the municipal drainage pipeline. It is planned to use a $1.5 \mathrm{ZDK}-20$ pump to pump it out. The treated mud shall be transported to a third party for discharge according to the traditional method. The haul distance shall be assumed to be $50 \mathrm{~km}$. The conventional mud carrier on the site shall be adopted (156 horsepower, the maximum speed is $103 \mathrm{~km} / \mathrm{h}$, and the carrying capacity is $8 \mathrm{~m}^{3}$ ).

New mud treatment technology is used for construction. According to on-site statistics, the mud can be treated at $10 \mathrm{~m}^{3}$ per hour. $40 \mathrm{~m}^{3}$ of mud shall be treated with $80 \mathrm{~m}^{3}$ of water, and $15 \mathrm{~m}^{3}$ of water shall be refilled in the water tank after treatment, which will take one hour.

Table 6

\begin{tabular}{|c|c|c|c|c|}
\hline \multirow[t]{2}{*}{ Processing method } & \multicolumn{2}{|c|}{ Construction link (code) } & \multicolumn{2}{|c|}{$\begin{array}{c}\text { Energy consumption (code), in terms } \\
\text { of electricity }\end{array}$} \\
\hline & \multicolumn{2}{|l|}{$\left[10 \mathrm{~m}^{3}\right]$} & {$[\mathbf{k V}$} & \\
\hline \multirow{3}{*}{$\begin{array}{c}\text { New Green Mud } \\
\text { Circulating Treatment } \\
\text { System }\left(E_{\mathrm{hb}}\right)\end{array}$} & The water cycle $\left(e_{11}\right)$ & 1 & $\left(p_{11}\right)$ & 15.188 \\
\hline & Mud separation $\left(e_{12}\right)$ & 1 & $\left(p_{12}\right)$ & 5.5 \\
\hline & Sand forming $\left(e_{13}\right)$ & 0.45 & $\left(p_{13}\right)$ & 0.2 \\
\hline \multirow{3}{*}{$\begin{array}{l}\text { A domestic comparable } \\
\text { product }\left(E_{\mathrm{db}}\right)\end{array}$} & Mud separation $\left(e_{21}\right)$ & 1 & $\left(p_{21}\right)$ & 4.5 \\
\hline & The drainage $\left(e_{22}\right)$ & 0.4 & $\left(p_{22}\right)$ & 0.5 \\
\hline & Mud transport $\left(e_{23}\right)$ & 0.6 & $\left(p_{23}\right)$ & 71.711 \\
\hline
\end{tabular}

Energy consumption parameters of each module in the construction stage 
It is assumed that $10 \mathrm{~m}^{3}$ of construction mud is processed. According to field test statistics, the proportion of recycled materials such as sand and aggregate produced can be $45 \%$. That is to say, when $20 \mathrm{~m}^{3}$ construction mud is input, $9 \mathrm{~m}^{3}$ sand and aggregate can be produced. The energy consumption parameters of each module in the construction stage are shown in Table 6.

The above two methods are used to treat $10 \mathrm{~m}^{3}$ building mud. The calculation process of comprehensive energy consumption is shown in Equations (10) and (11).

$$
\begin{aligned}
E_{\mathrm{hb}} & =\mathrm{e}_{11} \cdot p_{11}+\mathrm{e}_{12} \cdot p_{12}+\mathrm{e}_{13} \cdot p_{13} \\
& =1 \cdot 15.188+1 \cdot 5.5+0.45 \cdot 0.2 \\
& =20.788 \mathrm{kWh} \\
E_{\mathrm{db}} & =\mathrm{e}_{21} \cdot p_{21}+\mathrm{e}_{22} \cdot p_{22}+\mathrm{e}_{23} \cdot p_{23} \\
& =1 \cdot 4.5+0.4 \cdot 0.5+0.6 \cdot 71.711 \\
& =47.727 \mathrm{kWh}
\end{aligned}
$$

Therefore, for every $10 \mathrm{~m}^{3}$ construction mud treated with green mud recycling technology, the energy-saving compared to similar products is:

$$
\Delta E=E_{\mathrm{db}}-E_{\mathrm{hb}}=26.947 \mathrm{kWh}
$$

According to the calculation results in the previous section, the energy-saving energy is converted into standard coal by Eq. (5) and (6) as follows:

$$
\Delta T_{\mathrm{c}}=\Delta E \cdot 0.287=7.734 \mathrm{kgce}
$$

The reduction in $\mathrm{CO}_{2}$ emissions is:

$$
\Delta T_{c o_{2}}=\Delta E \cdot 0.705=18.998 \mathrm{kgCO}_{2}
$$

Therefore, it is easy to calculate that the total energy saving of 724 piles in the whole case project is 59.459 tce, and the emission reduction of the project is $146.053 \mathrm{tCO}_{2}$, with outstanding energy-saving and emission reduction effect.

According to the latest information, the total length of China's highways in 2019 was $5.013 \cdot 10^{6} \mathrm{~km}, 1.66 \cdot 10^{5} \mathrm{~km}$ more than the previous year, and $127.08 \%$ more than the same period last year from the Ministry of Transport. If all the waste mud is treated with the new mud treatment technology, it is estimated according to the calculation results of the case project that $8.965 \cdot 10^{5}$ tce can be saved and $2.202 \cdot 10^{6} \mathrm{tCO}_{2}$ can be reduced. This technology can bring huge social benefits and an economy.

\section{Conclusion}

Promoting energy conservation and emission reduction in the industry is an essential means of building a green future and achieving harmony between human society and nature. This study establishes an evaluation system including social, economic, and environmental rules. It evaluates the energy consumption and carbon emanations potential of waste mud in the construction industry based on rough set theory. Through the mutual restriction of the three rule layers, the rule layer's internal index weight is determined. The rule layer's overall weight is determined concurring to the actual situation of the industry's development to guarantee the objectivity and viability of the assessment comes about. On the premise of determining the energy-saving and emission reduction potential of 
building mud in Guangdong Province, this paper quantitatively calculates the benefits of energy-saving and emanation decrease agreeing to the specific construction technology.

The relevant data of Guangdong Province from 2006 to 2017 are selected to calculate the weight. The results show that the energy-saving and emanation decrease agreeing potential of building mud in Guangdong Province shows an overall upward trend. The evaluation results are steady with the real circumstance. The evaluation results and the changing trend of investment amount can be roughly divided into three stages. When the amount of investment in transportation construction increases rapidly, the evaluation result also increases gradually. After being affected by the policy, the investment amount remains stable, while the evaluation results fluctuate considerably. In the recent period, the construction investment and evaluation results have shown an upward trend. Compared with the evaluation results of building mud energy saving and emission reduction in Guangdong Province and the changing direction of highway mileage growth, both of them decreased from 2013 to 2015 and generally maintained different growth rates. The evaluation results show that although the policy impact has apparent effects, it is inflexible in the economy and industry's rapid development. According to industry development law, the government suggests that the government formulate scientific and reasonable norms while developing policies. To achieve efficient guidance for the development of energy conservation and emission reduction in the construction industry, at the same time, we should encourage and promote new energy conservation and emission reduction technologies to improve the overall level of development. Taking a Guangdong Province project as an example, the energy-saving and emission reduction benefits of the new treatment technology of building waste mud are calculated. The results show that the energy-saving benefit of 59.459 tce is achieved, and the carbon dioxide emission is reduced by 146.053 tonne. It is in line with the social, economic, and environmental goals and expectations and has good promotion potential. It also has particular reference significance for the construction treatment of energy saving and emission reduction of construction industry mud worldwide.

\section{Acknowledgements}

This work was supported by the Key Project of Xihua University (Z201036).

\section{References}

[1] Zhang H, Chen J, Li Y, Seiler MJ. Does the Development of China's Building Industry Influence the Global Energy Consumption and Carbon Emissions? an Analysis Based on the GVAR Model. Singapore: Springer; 2018. DOI: 10.1007/978-981-10-6190-5_58.

[2] Governments, USaC. U.S.-China Joint Announcement on Climate Change. 2014. Available from: https://obamawhitehouse.archives.gov/the-press-office/2014/11/11/us-china-joint-announcement-climatechange.

[3] Jiang J, Ye B, Liu J. Peak of $\mathrm{CO}_{2}$ emissions in various sectors and provinces of China: Recent progress and avenues for further research. Renew Sust Energy Rev. 2019;112:813-33. DOI: 10.1016/j.rser.2019.06.024.

[4] IPCC (2008). 2006 IPCC Guidelines for National Greenhouse Gas Inventories. Available from: https://www.ipcc.ch/report/2006-ipcc-guidelines-for-national-greenhouse-gas-inventories/.

[5] IPCC (2019). 2019 Refinement to the 2006 IPCC Guidelines for National Greenhouse Gas Inventories. Available from: https://www.ipcc.ch/report/2019-refinement-to-the-2006-ipcc-guidelines-for-nationalgreenhouse-gas-inventories/.

[6] Lin $\mathrm{BQ}, \mathrm{Xu}$ B. Growth of industrial $\mathrm{CO}_{2}$ emissions in Shanghai city: Evidence from a dynamic vector autoregression analysis. Energy Oxford. 2018;151:167-77. DOI: 10.1016/j.energy.2018.03.052. 
[7] Wen L, Zhang X. $\mathrm{CO}_{2}$ emissions in China's Yangtze River Economic Zone: A dynamic vector autoregression approach. Pol J Environ Stud. 2019;28:923-33. DOI: 10.15244/pjoes/83668.

[8] $\mathrm{Xu} \mathrm{B}$, Lin BQ. What cause a surge in China's $\mathrm{CO}_{2}$ emissions? A dynamic vector autoregression analysis. J Clean Prod. 2016;143:17-26. DOI: 10.1016/j.jclepro.2016.12.159.

[9] $\mathrm{Xu} \mathrm{B}$, Lin BQ. Assessing $\mathrm{CO}_{2}$ emissions in China's iron and steel industry: A dynamic vector autoregression model. Appl Energy. 2016;161:357-86. DOI: 10.1016/j.apenergy.2015.10.039.

[10] Hao H, Geng Y, Li W, Guo B. Energy consumption and GHG emissions from China's freight transport sector: Scenarios through 2050. Energy Policy. 2015;85:94-101. DOI: 10.1016/j.enpol.2015.05.016.

[11] Shao S, Liu J, Geng Y, Miao Z, Yang Y. Uncovering driving factors of carbon emissions from China's mining sector. Appl Energy. 2016;166:220-38. DOI: 10.1016/j.apenergy.2016.01.047.

[12] Huang WL, Yin X, Chen WY. Prospective scenarios of CCS implementation in China's power sector: An analysis with China TIMES. Energy Procedia. 2014;61:937-40. DOI: 10.1016/j.egypro.2014.11.999.

[13] Lin B, Moubarak M, Ouyang XL. Carbon dioxide emissions and growth of the manufacturing sector: Evidence for China. Energy. 2014;76:830-7. DOI: 10.1016/j.energy.2014.08.082.

[14] Shi Q, Chen J, Shen L. Driving factors of the changes in the carbon emissions in the Chinese construction industry. J Clean Prod. 2017;(166):615-27. DOI: 10.1016/j.jclepro.2017.08.056.

[15] Yang T, Pan Y, Yang Y, Lin M, Qin B, Xu P, et al. $\mathrm{CO}_{2}$ emissions in China's building sector through 2050: A scenario analysis based on a bottom-up model. Energy. 2017;128:208-23. DOI: 10.1016/j.energy.2017.03.098.

[16] Ai F, Yin X, Hu R, Ma H, Liu W. Research into the super-absorbent polymers on agricultural water. Agr Water Manage. 2021:106513. DOI: 10.1016/j.agwat.2020.106513.

[17] Zhang X, Zang C, Ma H, Wang Z. Study on removing calcium carbonate plug from near wellbore by high-power ultrasonic treatment. Ultrason Sonochem. 2020:104515. DOI: 10.1016/j.ultsonch.2019.03.006.

[18] Mo L, Sun W, Jiang S, Zhao X, Ma H, Liu B, et al. Removal of colloidal precipitation plugging with high-power ultrasound. Ultrason Sonochem. 2020;69:105259. DOI: 10.1016/j.ultsonch.2020.105259.

[19] Liu W, Ma H, Walsh A. Advance in photonic crystal solar cells. Renew Sust Energy Rev. 2019;116:109436. DOI: 10.1016/j.rser.2019.109436.

[20] Ma H, Zhang X, Ju F, Tsai SB. A study on curing kinetics of nano-phase modified epoxy resin. Sci Rep. 2018;8. DOI: 10.1038/s41598-018-21208-0.

[21] Ma H, Tsai SB. Design of research on performance of a new iridium coordination compound for the detection of $\mathrm{Hg}^{2+}$. Int J Env Res Pub HE. 2017;14. DOI: 10.3390/ijerph14101232.

[22] Yang G, He XL, Li JF, Jia XJ. The research of water resource sustainable utilization in Manas River. Acta Ecologica Sinica. Available from: https://www.oalib.com/paper/1402574.

[23] Gendron C. Beyond environmental and ecological economics: Proposal for an economic sociology of the environment. Ecol Econ. 2014;105:240-53. DOI: 10.1016/j.ecolecon.2014.06.012.

[24] Men B, Liu H, Tian W, Liu H. Evaluation of sustainable use of water resources in Beijing based on rough set and fuzzy theory. Water. 2017;9:852. DOI: 10.3390/w10070925.

[25] Wu X, Wen QB, Hu LM, Liu MY. Evaluation of unconventional water resources based on knowledge granularity. E3S Web Conf. 2020;144(1-3):01004. DOI: 10.1051/e3sconf/202014401004.

[26] Pawlak Z. Rough sets. Int J Comput Inform Sci. 1982;11:341-56. DOI: 10.1007/BF01001956.

[27] Pawlak Z. Rough classification. Int J Man Mach Stud. 1984;20:469-83. DOI: 10.1016/S0020-7373(84)80022-X.

[28] Pawlak Z. Rough sets and intelligent data analysis. Inform Sci. 2002;147:1-12. DOI: 10.1016/S0020-0255(02)00197-4.

[29] Pawlak Z, Skowron A. Rough sets: Some extensions. Inform Sci. 2007;177:28-40. DOI: 10.1016/j.ins.2006.06.006. 